\title{
Un enfoque de profesionalización crítico reflexivo para mejorar la enseñanza
}

Ana Rosa Arceo Luna

$\mathrm{E}$ $\mathrm{n}$ el ámbito docente, innumerables ocasiones he encontrado excelentes profesionistas especialistas en variados y diversos ámbitos, quienes tuvieron que desempeñarse en la docencia; por necesidad, por ser una oportunidad laboral, por suplir a algún compañero y en algunos reducidos casos, por gusto; sin embargo, cualquiera que haya sido la oferta inicial, quien elige desempeñarse como docente requiere una profesionalización como profesor, es decir, una especialización continua y siempre inconclusa que responda a las necesidades contemporáneas de su acción educativa, por lo que al no contar con una formación específica sobre los procesos de enseñanza y de aprendizaje, la opción es un proceso autoformativo crítico que vaya dando respuesta a las exigencias de cada grupo escolar y las políticas contemporáneas.

La profesionalización del docente requiere de una formación, más allá de los contenidos propios de la disciplina que imparte, la cual le provea las competencias necesarias para ejercer su labor como profesor, y los recursos para ir perfeccionando esta labor mediante la misma práctica. Esta formación implica una especialización pedagógica, como menciona Francisco Imbernón (1997), ha de fundamentarse en el desarrollo de habilidades para:

- Dirigir el proceso de enseñanza aprendizaje de la disciplina que imparte.

- Investigar el propio proceso para su perfeccionamiento.

- Incrementar su autonomía y control del propio trabajo.

- Poseer un cuerpo de contenidos científicos consistentes, y a su vez una ética compartida.

La primera de estas habilidades evoca una de las cuestiones pedagógicas más amplias, ¿cómo dirigir el proceso de aprendizaje? Por lo que el desarrollo del análisis de la profesionalización de los docentes se centrará en ella desde un enfoque crítico reflexivo. Sin pretender dar una respuesta exhaustiva a esta interrogante, se hace una reflexión inicial desde el paradigma sociocultural; partiendo de la comprensión sobre quién es el profesor que guía y dirige los procesos de aprendizaje en la educación superior.

El docente, como agente cultural, ejerce la labor de la enseñanza en un contexto de prácticas y medios determinados por las políticas educativas y la sociedad misma, asumiendo una función mediadora entre el saber sociocultural y los procesos de apropiación de los alumnos; es decir, la mediación entre la realidad contextual y el proceso mismo de aprendizaje de los educandos. Es el encargado de diseñar estrategias que promuevan el aprendizaje, provocando desafíos y retos que hagan cuestionar los significados y sentidos, todo ello orientado hacia una modificación de los esquemas de aprendizaje (Chaves, 2001).

Por lo tanto, desde el enfoque sociocultural, el profesor se convierte en ese mediador capaz de motivar a una modificación de los esquemas de aprendizaje y, en consecuencia, de las estructuras sociales en sí mismas.

Entonces, al ser un trabajo tan complejo y al tener un impacto trascendental en la sociedad, 
se debe considerar que el profesionista que desempeña la labor docente, ha de hacer patente su necesidad de profesionalizarse a fin de ser un agente crítico en sí mismo, y dar respuesta a las características propias del contexto en el cual se desarrollan los alumnos (Freire, 2006).

Uno de los primeros aspectos en los que encuentran dificultad muchos docentes nuevos en el ámbito es el desarrollo del trabajo curricular, del cual se desprenden las sesiones de aprendizaje, concretadas en la planeación de cada clase para responder con ello a los objetivos trazados en el programa de la materia correspondiente a un perfil de egreso determinado. Con base en lo anterior, el profesor competentemente formado será capaz de definir objetivos claros que deriven en instrumentos de evaluación confiables, válidos y pertinentes. ${ }^{1}$

Para el desarrollo de esta habilidad, es necesario un conocimiento del modelo educativo de la institución, los contenidos curriculares, el plan de estudios, entre otros documentos de apoyo; pero el docente profesional trasciende de la planeación surrealista a un diseño que se implementa en la realidad práctica. Esto, mediante una habilidad crítico reflexiva que, como menciona Paulo Freire (2002, citado en Pineda, 2008), implica ser un agente activo que al reconocer su propio ser, y a través de la interacción con el otro, no es sólo un reproductor de los procesos de aprendizaje, sino que es capaz de desarrollarse a sí mismo a fin de intervenir en su medio.

Desde un enfoque crítico reflexivo, la habilidad de planeación y diseño curricular, se desarrolla mediante la evaluación diaria del propio desempeño y el impacto causado en los alumnos, ya que la reflexión constante de lo que se hace y la crítica personal de cómo se hace, posibilita integrar los planteamientos plasmados en los documentos curriculares con una implementación realista en las aulas.

No obstante, una práctica desde este enfoque tiende, por su naturaleza, a una acción subjetiva. Por ello, es necesario tomar conciencia del impacto

\footnotetext{
Validez: las preguntas tienen congruencia con objetivos y contenidos del programa establecido por la academia. Confiabilidad: se refiere a la consistencia de los resultados de la evaluación, de tal forma que diferentes puntajes reflejan diversos niveles de competencia de los sustentantes. Pertinencia: toma en cuenta los diferentes contenidos enseñados y cubre de manera representativa los dominios definidos como objeto de evaluación (Ceneval, 2010).
}

que se genera en los demás con las decisiones en torno a la enseñanza. Por lo tanto, un profesor que asume una postura realmente crítica y reflexiva de su labor, requiere necesariamente estar inmerso en un enfoque sociocultural que contemple a los educandos, y particularmente, que provea evidencia empírica para generar las reflexiones, además que integre un método científico usando los resultados de las evaluaciones parciales y los comentarios de los estudiantes, para una crítica más objetiva.

\section{Haciendo crítica reflexiva desde lo sociocultural}

Lev Vigotsky (en Hernández, 2004), a través de su paradigma sociocultural, explica que el aprendizaje se desarrolla mediante la construcción de esquemas de pensamientos, fruto de la interacción con otros. Pero esta interacción no reside en la sola orientación de actividades al trabajo en equipo entre los alumnos, las discusiones y los recursos tecnológicos que proponen redes de comunicación.

El papel del docente trasciende más allá de la sola orientación de actividades con este carácter. El profesor se convierte en un observador capaz de analizar la realidad, fraccionar los elementos que en ella interactúan y tomar decisiones con ellos y para ellos. Por lo que, al hacer una reflexión y crítica de su labor, le permite no sólo mejorar el aprendizaje de forma vertical (alumno-docente), sino que estas reflexiones le ayudarán a consentir las relaciones entre los alumnos, haciendo uso explícito del lenguaje con la intención de promover la situación de intersubjetividad y la negociación de significados. De tal forma que, al diseñar un instrumento para la evaluación (un examen escrito, un portafolio de evidencias, una exposición por equipos, un ensayo, entre otros), el profesor logre una visión panorámica que le permita contemplar holísticamente el contexto donde el alumno ha construido sus saberes (Hernández, 2004), así como los actores que han sido parte de la construcción de esos saberes.

Finalmente, la profesionalización docente implicará también un conocimiento y uso de las estrategias de enseñanza, fundamentadas en la observación del profesor a su interacción con sus alumnos, y la que se da entre ellos mismos; a partir de esto, es fundamental generar una reflexión 


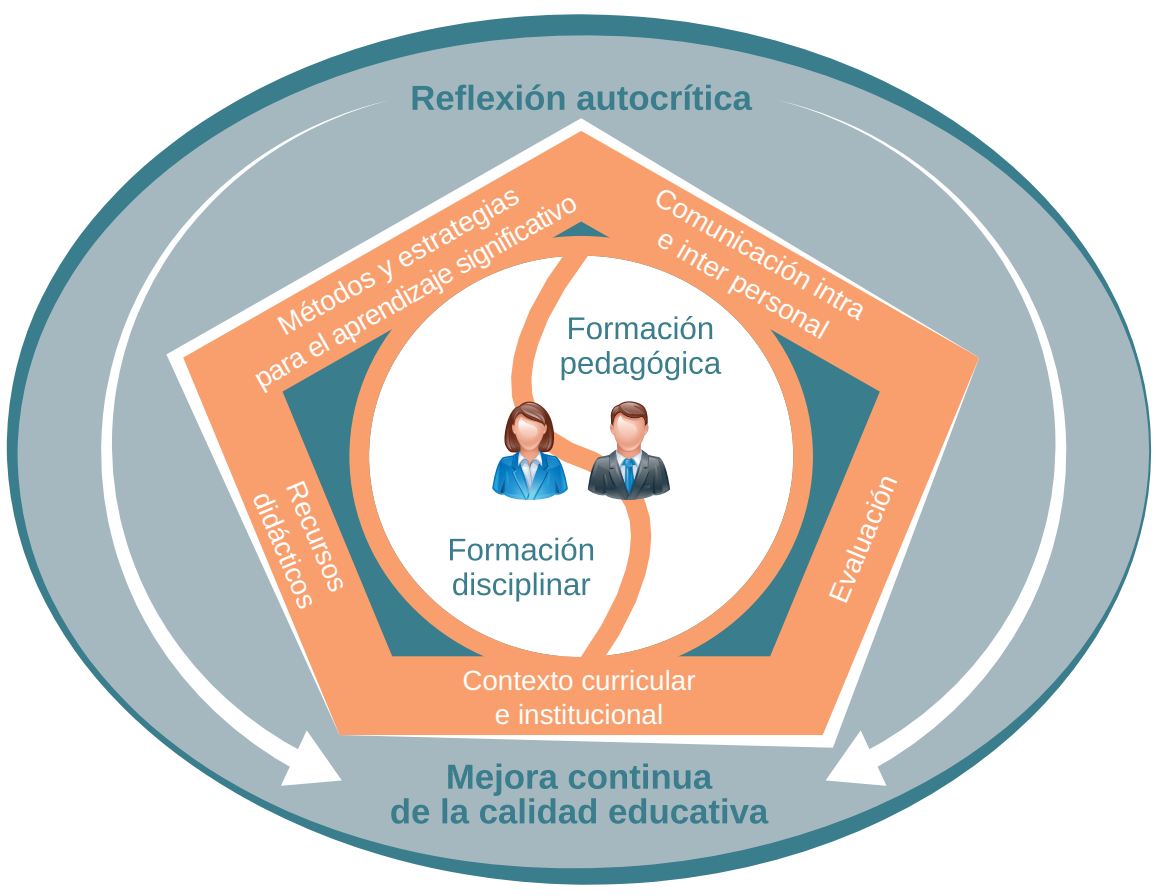

basada en las propias características del grupo, los recursos y el tiempo disponibles, además de otros elementos que signifiquen la adecuada selección de las estrategias, para concluir en una crítica sobre el desarrollo de sus clases, la cual le aporte elementos para mejorar su práctica, e incluso, lo lleve a explorar distintas estrategias didácticas.

\section{Conclusiones}

El ser docente requiere una profesionalización que provea, además de los elementos pedagógicos básicos, una visión donde las interacciones entre los educandos, el medio social y cultural, así como los lineamientos institucionales, adquieran relevancia para la dirección de los procesos de enseñanza.

A partir de su conciencia sobre el dinamismo y la estrecha integración de esos elementos, el docente podrá asumir una postura crítico reflexiva que lo sitúe en una continua evaluación, y evaluar es abrir las puertas a la mejora. Por ello, no basta con la especialización disciplinar en las distintas áreas, es indispensable desarrollar competencias docentes críticas y reflexivas, traducidas en decisiones que tiendan a la continua búsqueda de mejorar los procesos educativos, partiendo de las realidades de cada aula, más allá de una valoración subjetiva o de las estadísticas institucionales propiamente dichas.
Este enfoque es una propuesta que busca traducir los planteamientos pedagógicos en estrategias docentes que faciliten y promuevan la mejora en los procesos de aprendizaje, al tiempo que se cumpla con los programas institucionales.

\section{Fuentes de consulta}

Ceneval. (2010). La evaluación con peras y con manzanas. México. Recuperado de: http:// bit.ly/1KWgzkf.

Chaves Salas, A. L. (2001). Implicaciones educativas de la teoría de Vigotsky. Educación, Vol. 25, Núm. 2, 59-65.

Freire, P. (2006). Pedagogía de la autonomía. Saberes necesarios para la práctica educativa (11ed.). México: Siglo XXI Editores.

Hernández Rojas, G. (2004). Paradigmas en Psicología de la Educación. México: Paidós Educador.

Imbernón, F. (1997). La formación del profesorado. España: Paidós.

Pineda Ibarra, R. (2008). La concepción de "ser humano" en Pablo Freire. Revista Educare, Vol. xII, Núm. 1, 47-55. Hereida, Costa Rica. Recuperado el 27 de febrero de 2015, en: http://bit.ly/1FLxqus. 